Revista Brasileira de Farmacognosia Brazilian Journal of Pharmacognosy 22(3): 604-610, May/Jun. 2012

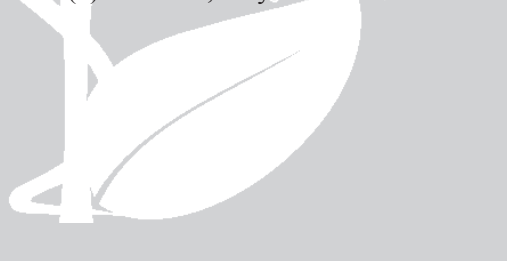

Article

Received 10 Jun 2011

Accepted 3 Oct 2011

Available online 17 Jan 2012

Keywords:

Ficus benghalensis

hepatotoxicity

isoniazid

oxidative stress

rifampicin

ISSN 0102-695X

http://dx.doi.org/10.1590/S0102-

$695 \times 2012005000009$

\section{Protective role of Ficus benghalensis against isoniazid-rifampicin induced oxidative liver injury in rat}

\author{
S. Angala Parameswari, ${ }^{1, *}$ T. S. Mohamed Saleem, ${ }^{2}$ K. B. \\ Chandrasekar, ${ }^{3}$ C. Madhusudhana Chetty ${ }^{4}$
}

\author{
${ }^{1}$ Department of Pharmaceutical Analysis, Annamacharya College of Pharmacy, \\ India, \\ ${ }^{2}$ Department of Pharmacology, Annamacharya College of Pharmacy, India, \\ ${ }^{3}$ Department of Chemistry, JNT University Anantapur, India, \\ ${ }^{4}$ Department of Biotechnology, Annamacharya College of Pharmacy, India.
}

\begin{abstract}
The present study was made to investigate the protective effect of methanolic extract of Ficus benghalensis L., Moraceae, on isoniazid-rifampicininduced hepatotoxicity in rats. Rats were divided into six different groups; group 1 served as a control, group 2 received isoniazid and rifampicin (100 mg/ $\mathrm{kg}$, i.p.), in sterile water, groups 3,4 and 5 received $100,200 \& 300 \mathrm{mg} / \mathrm{kg} \mathrm{bw}$, p.o. methanolic extract of $F$. benghalensis and group 6 received Liv 52. All the treatment protocols followed 21 days and after rats were sacrificed blood and liver were used for biochemical and histological studies, respectively. Administration of isoniazid and rifampicin caused a significant elevation in the levels of liver marker enzymes $(p<0.05$ and $p<0.01)$ and thiobarbituric acid reactive substances $(p<0.001)$ in experimental rats. Administration of methanolic extracts of $F$. benghalensis significantly prevented isoniazid-rifampicin-induced elevation in the levels of serum diagnostic liver marker enzymes and TBARS level in experimental groups of rats. Morever, total protein and reduced glutathione levels were significantly $(p<0.001)$ increased in treatment group. The effect of extract was compared with a standard drug, Liv 52. The changes in biochemical parameters were supported by histological profile. It is to be concluded that the methanolic extract of $F$. benghalensis protects against isoniazid and rifampicin-induced oxidative liver injury in rats.
\end{abstract}

\section{Introduction}

Drug-induced liver toxicity is a common cause of liver injury. It accounts for approximately one-half of the cases of acute liver failure and mimics all forms of acute and chronic liver disease (Kaplowitz, 2001). Different types of drugs such as acetaminophen, chloroquine and isoniazid are inducers of hepatotoxicity in world. Isoniazid and rifampicin, the first line drugs used for tuberculosis therapy are associated with hepatotoxicity (Tasduq et al., 2005). ${ }^{2}$ The rate of hepatotoxicity has been reported to be much higher in developing countries like India (8-30\%) compared to that in advanced countries (2-3\%) with a similar dose schedule (Sharma, 2004).

Ficus benghalensis L., Moraceae (Mulberry family), is commonly known as a Banyan tree or Vata or Vada tree in ayurveda. There are more than 800 species and 2000 varieties of Ficus species, most of which are native to the old world tropics. F. benghalensis is a remarkable tree from India that sends down its branches and great number of shoots, which take root and become new trunks. This tree is considered to be sacred in many places in India. Earlier, glucoside, 20-tetratriaconthene-2-one, 6-heptatriacontene10 -one, pentatriacontan-5-one, $\beta$-sitosterol- $\alpha$-D-glucose, and meso-inositol have been isolated from the bark of the F. benghalensis (Subramanian \& Misra, 1978; The Wealth of India, 1999)

The hanging roots of $F$. benghalensis have been reported as anti-diarrhoeal agents (Mukherjee et al., 1998). The bark of this plant reported for wound healing activity (Garg \& Paliwal, 2011). The fruit extract of F. benghalensis has been documented for its anti-tumor and anti bacterial activities (Mousa et al., 1994; Singh \& Watal, 2010). The extracts of $F$. benghalensis were also reported to inhibit insulinase activity from the liver and kidney (Achrekar et al., 1991). It was also found to inhibit the lipid peroxidation (Shukla et al., 2004). Various extracts of F. benghalensis were screened for its analgesic, anti-pyretic, anti-allergic and anti-stress potential in asthma by milk-induced leucocytosis and milk-induced eosinophilia (Yadav et 
al., 2011; Taur et al., 2007). Other species of Ficus viz. F. carica (Gond \& Khadabadi, 2008), F. glomerata (Kubsad et al., 2008), and F. racemosa (Mandal et al., 1999) were found to have hepatoprotective activity. Based on this, an attempt has been made to evaluate the hepatoprotective effect of $F$. benghalensis.

\section{Material and Methods}

\section{Chemicals}

Bilirubin, total protein, alkaline phosphatase (ALP), alanine transaminases (ALT), and aspartate transaminases (AST) were assayed by using kits from Ranbaxy Diagnostic, New Delhi. All the drugs, chemicals and reagents used for biochemical estimation were purchased from Sigma-Aldrich, USA.

Animals

Male Wistar albino rats, weighing about 150-200 $\mathrm{g}$ and Swiss albino mice weighing about 25-30 g were obtained from Institute Animal Center and used in the experiments. The protocol was approved by the Institute's Animal Ethical Committee (1220/a/08/CPCSEA/ ANCP/04). Animals were kept in the animal house at an ambient temperature of $25{ }^{\circ} \mathrm{C}$ and $45-55 \%$ relative humidity, with $12 \mathrm{~h}$ each of dark and light cycles. Animals were fed pellet diet and water ad-libitum.

\section{Preparation of plant extract}

Aerial root of Ficus benghalensis L., Moraceae, were collected from Rajampet, Andhrapradesh in June 2009 and identified by Dr. K. Madhava Chetty, Department of Botany, Sri Venkateswara University, Tirupathi. The voucher specimen (ANCP-MP-88) has been deposited in the parent department. The shade dried roots were powdered to get a course granule. About $500 \mathrm{~g}$ of dried powder was extracted with various solvents (petroleum ether, hexane, benzene, chloroform, ethyl acetate, methanol, ethanol and water) by continuous hot percolation, using soxhlet apparatus. The resulted dark-brown extract were concentrated up to $100 \mathrm{~mL}$ on rotavapor under reduced pressure. The concentrated crude extracts were lyophilized into powder and used for the study.

\section{Phytochemical screening}

The extracts obtained were subjected to preliminary phytochemical screening and thin layer chromatography to identify the chemical constituents. TLC was performed by using mobile phase n-hexane:ethyl acetate in the ratio of 9:1 and the compound present in the sample were detected under UV chamber at $365 \mathrm{~nm}$. The methods of analysis employed were those described in standard procedures (Harborne \& Baxter, 1993; Trease \& Evans, 1989).

Table 1. Effect of Ficus benghalencis in different biochemical parameters in INH+RIF induced hepatotoxic rats.

\begin{tabular}{|c|c|c|c|c|c|c|}
\hline Groups & Total bilirubun $\mathrm{mg} / \mathrm{dL}$ & Total protein $\mathrm{mg} / \mathrm{dL}$ & Albumin mg/dL & SGOT IU/dL & SGPT IU/dL & ALP IU/dL \\
\hline Normal control (G1) & $0.43 \pm 0.02$ & $13 \pm 0.77$ & $4.2 \pm 0.24$ & $187 \pm 11$ & $69 \pm 0.63$ & $261 \pm 32$ \\
\hline Toxic control (G2) & $0.57 \pm 0.14^{\mathrm{ns}}$ & $11 \pm 0.23^{\#}$ & $3.5 \pm 0.22^{\#}$ & $239 \pm 18^{\# \#}$ & $122 \pm 27^{\#}$ & $308 \pm 38^{\mathrm{ns}}$ \\
\hline Liv 52 Group (G3) & $0.37 \pm 0.04^{\mathrm{ns}}$ & $12 \pm 0.23^{\mathrm{ns}}$ & $4.4 \pm 0.09 * *$ & $149 \pm 1.1 * * *$ & $54 \pm 1.8^{* *}$ & $250 \pm 26^{\mathrm{ns}}$ \\
\hline MEFB 100 mg/kg (G4) & $0.53 \pm 0.08^{\mathrm{ns}}$ & $12 \pm 0.26^{\mathrm{ns}}$ & $3.6 \pm 0.16^{\mathrm{ns}}$ & $175 \pm 3.6 * * *$ & $94 \pm 15 \mathrm{~ns}$ & $256 \pm 24^{\mathrm{ns}}$ \\
\hline MEFB 200 mg/kg (G5) & $0.33 \pm 0.02^{\mathrm{ns}}$ & $12 \pm 0.06^{\mathrm{ns}}$ & $4.4 \pm 0.17 * *$ & $158 \pm 3.7 * * *$ & $66 \pm 1.1 *$ & $266 \pm 16^{\mathrm{ns}}$ \\
\hline MEFB 300 mg/kg (G6) & $0.73 \pm 0.11^{\text {ns }}$ & $13 \pm 0.31 *$ & $4.4 \pm 0.09 * *$ & $170 \pm 2.6^{* * *}$ & $67 \pm 1.7^{*}$ & $212 \pm 18^{\mathrm{ns}}$ \\
\hline
\end{tabular}

Values are expressed as ean \pm SEM; Values are find out by using ONEWAY ANOVA followed by Dunnett's multiple range tests; ${ }^{*} p<0.05$ vs Control (G1); ${ }^{* \#} p<0.01$ vs Control (G2); ${ }^{*} p<0.05$ vs Toxic Control (G2); ${ }^{* *} p<0.01$ vs Toxic Control (G2); ${ }^{* * *} p<0.001$ vs Toxic Control (G2); ns;-non significant.

Table 2. The levels of TBARS and GSH after the treatment of rats with isoniazid-rifampicin and MEFB on 21 days treatment.

\begin{tabular}{lcc}
\hline \multicolumn{1}{c}{ Group } & TBARS nmol/g wet wt & GSH $\mu \mathrm{g} / \mathrm{g}$ wet wt \\
\hline Normal control (G1) & $276.42 \pm 0.23$ & $91.13 \pm 0.14$ \\
Toxic control (G2) & $398.75 \pm 0.51^{\mathrm{a}}$ & $43.6 \pm 0.27^{\mathrm{b}}$ \\
Liv $5210 \mathrm{mg} / \mathrm{kg}$ (G3) & $245.21 \pm 0.31^{\#}$ & $94.52 \pm 0.36^{\#}$ \\
MEFB $100 \mathrm{mg} / \mathrm{kg}$ (G4) & $231.45 \pm 0.2^{\#}$ & $87.27 \pm 0.12^{\#}$ \\
MEFB $200 \mathrm{mg} / \mathrm{kg}$ (G5) & $254.61 \pm 0.7^{\#}$ & $98.15 \pm 0.6^{\sharp}$ \\
MEFB 300 mg/kg (G6) & $292.91 \pm 0.32^{\#}$ & $89.6 \pm 0.25^{\#}$
\end{tabular}

All values are expressed as means \pm SEM. Statistical analysis was done using One-way ANOVA followed by Post Test. ${ }^{a} p<0.001$ when compared with $\mathrm{G} 1,{ }^{\mathrm{b}} p<0.01$ when compared with $\mathrm{G} 1,{ }^{,} p<0.001$ when compared with $\mathrm{G} 2$. 
Acute toxicity study

Acute oral toxicity (AOT) of methanolic extract of $F$. benghalensis (MEFB) were determined using Swiss albino mice. The animals were fasted for $3 \mathrm{~h}$ prior to the experiment and were administered with single dose of extract dissolved in 5\% gum acacia (doses ranges from $500-5000 \mathrm{mg} / \mathrm{kg}$ at various dose levels) and observed for mortality up to $48 \mathrm{~h}$ (short term toxicity). Based on the short-term toxicity, the dose of next animal was determined as per OECD guideline 425 .

Free radical scavenging activity by 1,1-diphenyl-2-picryl hydrazyl (DPPH) method

In vitro antioxidant activity of MEFB was analyzed by DPPH method (Singh et al., 2002). Different concentrations $(10,50,100$ and $500 \mu \mathrm{g})$ of extract samples and Butylated hydroxyl anisole (BHA-synthetic antioxidant) were taken in different test tubes. The volume was adjusted to $500 \mu \mathrm{L}$ by adding methanol. Five milliliters of a $0.1 \mathrm{mM}$ methanolic solution of DPPH was added to these tubes and shaken vigorously. A control without the test compound, but with an equivalent amount of methanol was maintained. The tubes were allowed to stand at room temperature for $20 \mathrm{~min}$. The absorbance of the samples was measured at $517 \mathrm{~nm}$. Radical scavenging activity was calculated using the following formula: \% radical scavenging activity $=[$ (control Abs-sample Abs $) /$ Control Abs] $\times 100$.

\section{Induction of experimental hepatotoxicity}

Isoniazid and rifampicin solution were prepared separately in sterile distilled water. Rats were treated with isoniazid $(100 \mathrm{mg} / \mathrm{kg}$, i.p. $)$ and co-administered with rifampicin $(100 \mathrm{mg} / \mathrm{kg}$, i.p.), for 21 days (Yue et al., 2004; Saleem et al., 2008). In order to study the effect of MEFB in rat, 100, 200 and $300 \mathrm{mg} / \mathrm{kg}$ bw, p.o. were used respectively. Liv $52(10 \mathrm{mg} / \mathrm{kg}$ bw, p.o. $)$ was used as a standard drug in this study. Rats were divided into Six different groups $(n=6)$, group 1 was served as a control, group 2 was toxic control receive isoniazid+rifampicin (100 mg/kg bw i.p.), group 3, 4 and 5 were served as extract treatment groups received 100, $200 \& 300 \mathrm{mg} / \mathrm{kg}$ bw, p.o MEFB and group 6 served as standard group received Liv 52. Rats were treated as per the treatment protocol. Body weights of these rats were monitored sequentially in control and experimental animals for a period of 21 days.

\section{Biochemical estimation}

Rats were sacrificed $1 \mathrm{~h}$ after administration on day 21. The blood was collected by retro-orbital artery bleeding. Blood samples were centrifuged for $10 \mathrm{~min}$ at $3000 \mathrm{rpm}$ to separate the serum. ALP, ALT, AST, total protein and bilirubin levels were estimated from the serum by using standard kits (Rajesh et al., 2005). Liver was excised immediately, quickly cooled and perfused with cold normal saline. Ten percent homogenate was prepared by homogenizing the liver tissue by using $0.3 \mathrm{~m}$ phosphate buffer. TBARS (Okhawa et al., 1979) and GSH (Ellman, 1959) levels were estimated from the liver homogenate by using spectrophotometric determination.

\section{Histopathological studies}

The livers were excised quickly and fixed in $10 \%$ formalin and stained with haemotoxylin and eosin and then observed under microscope for degeneration, fatty changes or necrotic changes as evidence of hepatotoxicity.

\section{Statistics}

All values were expressed as means \pm SEM $(n=6$ in each group). One way ANOVA was applied to test for significance of biochemical data of the different groups. Significance is set at $p \leq 0.05$.

\section{Results}

\section{Phytochemical screening}

The freshly prepared extracts were subjected to preliminary phytochemical screening test for various constituents. All the extracts shows the presence of different chemical constituents and the methanolic extract revealed the presence of flavonoids, alkaloids and terpenoids. Based on this the methanolic extract was selected for pharmacological evaluation.

\section{Acute toxicity study}

Acute oral toxicity studies, the extracts treated animals were observed for mortality up to $48 \mathrm{~h}$. there was no mortality or any signs of behavioral changes observed after oral administration of methanol extract up to 5000 $\mathrm{mg} / \mathrm{kg}$ body weight.

\section{Free radical scavenging activity by DPPH method}

The free radical scavenging activity of MEFB and BHA were like at $10 \mu \mathrm{g} 4.06$ and $31.24 \%, 50 \mu \mathrm{g}$ 12.41 and $71.68 \%, 100 \mu \mathrm{g} 22.35,86.46 \%$ and $500 \mu \mathrm{g}$ $57.43 \%$, respectively. MEFB shows significant free radical scavenging activity at higher dose $(500 \mu \mathrm{g})$ when compared with other doses. The result was present in Figure 1. The free radical scavenging activity of BHA at $500 \mu \mathrm{g}$ is high and beyond the measurable limit. Hence indicated by the asterisk mark (*) in the data and not represented in the Figure 1. 


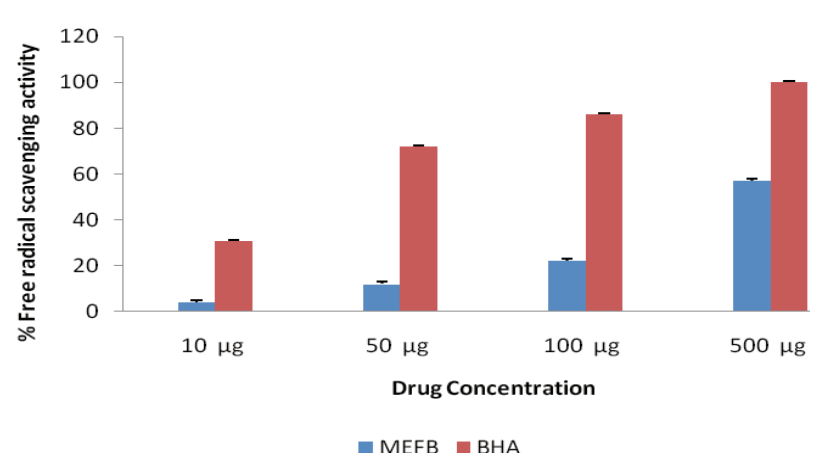

Figure 1. Free radical scavenging activity of MEFB of Ficus benghalensis.

\section{Mortality data}

There was no mortality occurred in control, toxic control and standard group. During the treatment period all the group of extract treatment group shows the death event like 3 in G4, 2 in G5 and 1 in G6, respectively. There was no significant difference in survival proportion. The body weight and relative liver weights of the experimental animals calculated at the end of the study had no statistically significant difference when compared to the control animals. The results were present in Figure 2.

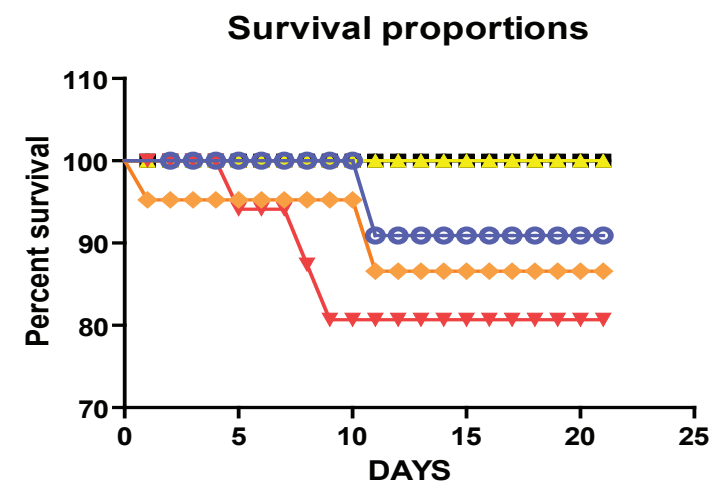

Figure 2. Survival proportions of rats of respective group during treatment period.

\section{Biochemical parameters}

There was no significant difference between control and other treatment group in total bilirubin level. There was a significant elevation of $(p<0.01)$ AST in $\mathrm{INH}+\mathrm{RIF}$ treated rats. It was significantly $(p<0.001)$ decreased by the administration of MEFB at a dose of 100 , 200 and $300 \mathrm{mg} / \mathrm{kg}$. There was a significant elevation of $(p<0.01)$ ALT in INH+RIF treated rats. It was significantly $(p<0.05)$ decreased by the administration of MEFB at a dose of 200 and $300 \mathrm{mg} / \mathrm{kg}$. In total protein level there was a significant difference $(p<0.01)$ between control and INH+RIF treated rats. But, there was no significant difference between treatment rats at a dose of 100 and 200 $\mathrm{mg} / \mathrm{kg}$ and only slightly increased level of $(p<0.05)$ total protein in $300 \mathrm{mg} / \mathrm{kg}$ of MEFB treated group. In albumin level also only 200 and $300 \mathrm{mg} / \mathrm{kg}$ treated rats shows the significant $(p<0.01)$ rise when compared with toxic control group. All the treatment groups show the data same like standard Liv 52 treated animals. The results were present in Table 1.

Increased liver TBARS level in toxic control group is indication for increased oxidative stress by treatment of INH+RIF. Increased liver TBARS significantly $(p<0.001)$ reduced by co-administration of MEFB in three different doses (100, 200 and 300 $\mathrm{mg} / \mathrm{kg} \mathrm{b.w}$ ) and Liv 52 treatment group. The INH+RIFadministered animals exhibited significantly $(p<0.01)$ low levels of hepatic GSH levels significantly increased by co-administration of MEFB and Liv 52 treatment group. The results were shown in Table 2 .

\section{Histopathological studies}

The liver of rats from respective groups were subjected to histopathological study. The results were present in Figure 3. Hepatocytes of the normal control group showed a normal lobular architecture of the liver (A). In the INH+RIF treated group the liver showed hepatocytic necrosis and inflammation and neutrophil infiltration also observed in the centrilobular region with portal triaditis (B). Liv 52 pretreated group showed minimal inflammation and hepatic congestion with moderate portal triditis and their lobular architecture was normal (C). MEFB pretreated group at al dose of 100, 200 and $300 \mathrm{mg}$ / $\mathrm{kg}$ showed minimal inflammation with moderate portal triditis and their lobular architecture was normal (D-F). These above findings indicate the hepatoprotective effect of extracts. However, MEFB showed minimal hepatocytes changes with dose dependent activity.

\section{Discussion}

Phytochemical screening of methanolic extract revealed the presence of flavonoids. We also reported the same by thin layer chromatography and HPTLC studies. In our previous report, TLC of methanolic extract performed by the mobile phase ethyl acetate: formic acid: glacial acetic acid: water in the ratio of $100: 11: 11: 26$ shows the single spot at $R_{f} 0.86$ with blue florescence under UV chamber at $365 \mathrm{~nm}$. The same conformed by HPTLC also (Parameswari et al., 2011). In the present study, hepatotoxicity model in Wistar albino rats was successfully produced by administering INH and RIF (100 mg/kg per day each i.p.). A marked rise above the normal upper limits in the measured serum transaminases in INH+RIF group on day 21 of the experiment was a biochemical indication of liver injury. 

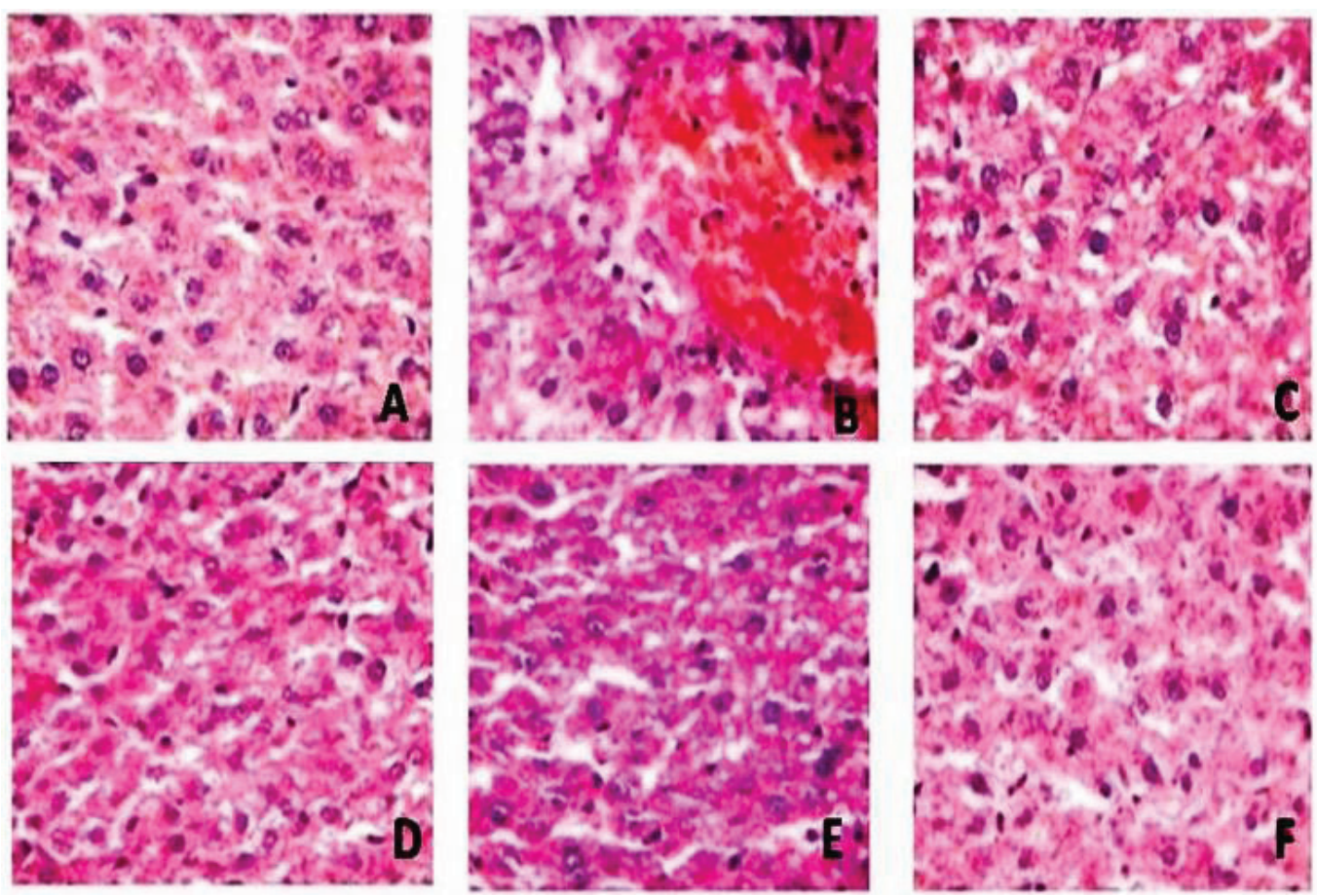

Figure 3. Histopathology report. A. Hepatocytes of the normal control group showed a normal lobular architecture of the liver; B. hepatocytes of toxic control group showed hepatocytic necrosis and inflammation and neutrophil infiltration also observed in the centrilobular region with portal triaditis; C. Liv 52 pretreated group showed minimal inflammation and hepatic congestion with moderate portal triditis and their lobular architecture was normal; D-F. MEFB pretreated group at all dose of $100,200 \mathrm{and} 300 \mathrm{mg} / \mathrm{kg}$ showed minimal inflammation with moderate portal triditis and their lobular architecture was normal.

During the metabolism of INH, hydrazine is produced directly (from INH) or indirectly (from acetyl hydrazine). From earlier study (Garner et al., 2004) it is evident that hydrazine play a role in INHinduced liver damage in rats, which is consistent with the report by Sarich et al., 1996. The combination of INH and RIF was reported to result in higher rate of inhibition of biliary secretion and an increase in liver cell lipid peroxidation, and cytochrome P450 was thought to be involved the synergistic effect of RIF on INH (Ramaiah et al., 2001). However, its role in INHinduced hepatotoxicity is unclarified, as INH itself is an inducer of CYP2E1 (Skakun \& Shmanko, 1985). In previous report also says that there did not seem to be clear evidence that Isoniazid proves much more injuries than Rifampicin and, in this connection, they consider that it is the combination of these two drugs that confer the additive, or even synergistic, potential of liver toxicity than either agent alone, as conjectured (Yasuda et al., 1990; Wu et al., 1990).

INH is metabolized in the liver primarily by acetylation and hydrolysis, and it is these acetylated metabolites that are thought to be hepatotoxins (Steele et al., 1991). Previous report in rats suggest that the hydrazine metabolite of INH and is subsequent effect on CYP2E1 induction is involved in the development of INH-induced hepatotoxicity (Yue et al., 2004). and also oxidative stress as one of the mechanism for INH+RIF induced hepatic injury (Peretti et al., 1987).

In this study the results suggest that the statistically significant different in biochemical parameters in toxic control group G2, indicate that hepatic damage has been induced by INH+RIF. Following treatment with Liv 52 and MEFB (100, 200 and $300 \mathrm{mg} / \mathrm{kg}$ ), all the parameters were reduced and total protein restored to normal value. Thakare et al., (2010) also reported that administration of methanolic extract of $F$. benghalensis revert the elevated level of serum liver marker enzymes and malondialdehyde (MDA) (an index of lipid peroxidation) formation in edematous tissue. at a dose of 200 and $400 \mathrm{mg} / \mathrm{kg}$. Histopathology also revealed that the significant protection from the hepatic damage by the treatment of MEFB.

Metabolism of chemicals takes place largely in the liver, which accounts for the organ's susceptibility to metabolism-dependent, drug induced injury. The drug metabolites can be electrophilic chemicals or free radicals that undergo or promote a variety of chemical reactions, such as depletion of reduced glutathione; covalently binding to proteins, lipids, or nucleic acids; or inducing lipid peroxidation (Kaplowitz, 2004). In present study in toxic control group increased level of TBARS (a marker for oxidative stress), reduction in the GSH concentration 
is indication for increased oxidative stress in INH+RIF treatment group. Elevation of TBARS were significantly reduced by co-administration of MEFB and Liv 52 and elevation of GSH level after MEFB and Liv 52 treatments indicate that the extracts is useful for the treatment of drug injury caused by INH+RIF. Moreover, the MEFB showing significant free radical scavenging activity at a dose of 500 $\mu \mathrm{g}$ also revealed that the extract having the therapeutic value against hepatotoxicity through reduction in oxidative stress. Recently we reported the same findings by using Annona squamosa in this INH-RIF induced hepatotoxic model (Mohamed Saleem et al., 2011).

The reason for hepatoprotective effect of the extracts may be that $F$. benghalensis contain flavonoids and terpenoids which might have scavenged the free radical offering hepato protection. Purification of extracts and identification of the active principle may yield a good hepatoprotective drug.

\section{Conclusion}

This study showed that MEFB protective action against the hepatotoxicity induced by the drugs used in the treatment of tuberculosis. The hepatoprotective role of MEFB might be due to its antioxidant potential mechanism suggesting that the extract of plant may be useful to prevent the oxidative stress induced damage. More research is required in this view point to develop a good hepatoprotective drug from aerial root of Ficus benghalensis. Purification of extracts and identification of the active principle may yield active hepatoprotective ingredients.

\section{References}

Achrekar S, Kaklaji GS, Pote MS, Kelkar SM 1991. Hypoglycemic activity of Eugenia Jambolana and Ficus benghalensis: Mechanism of action. In vivo 5: 143-147.

Ellman GL 1959. Tissue sulphydryl groups. Archives. Biochem Biophysics 82: 70-77.

Garg VK, Paliwal SK 2011. Wound-healing activity of ethanolic and aqueous extracts of Ficus benghalensis. J Adv Pharm Tech Res 2: 110-114

Garner P, Holmes A, Ziganahina L 2004. Tuberculosis. Clin Evid 11: 1081-1093.

Gond NY, Khadabadi SS 2008. Hepatoprtotective asctivity of Ficus carica leaf extract on rifampicin-induced hepatic damage in rats. Indian J Pharm Sci 70: 364-366

Harbone JB, Baxter HH 1993. Phytochemical Dictionary: A hand Book of Bioactive Compound from plants. Washington: Taylor and Francis; p.237.

Kaplowitz N 2004. Drug induced liver injury. Clin Infect Dis 38(Suppl 2): S44-S48.

Kaplowitz N 2001. Drug-induced liver disorders: implications for drug development and regulation. Drug Safety 24:
483-490.

Kubsad P, Channa B, Shrishailappa B, Suresh B 2008. Hepatoprotective and antioxidant activity of methanol extract of Ficus glomerata. J Nat Med 62: 379-383

Mandal SC, Maity TK, Das J, Pal M, Saha BP 1999. Hepatoprotective activity of Ficus racemosa leaf extract on liver damage caused by carbon tetrachloride in rats. Phytother Res 13: 430-432.

Mohamed Saleem TS, Ramkanth S, Alagusundaram S, Gnanaprakash K, Angalaparameswari S, Thiruvengadarajan VS, Gauthaman K 2011. Protective effect of methanolic extract of Annona squamosa Linn. in isoniazid-rifampicin induced hepatotoxicity in rats. Pak J Pharm Sci 24: 129-134.

Mousa O, Vuorela P, Kiviranta J, Wahab SA, Hiltunen R, Vourela H 1994. Bioactivity of certain Egyptian Ficus species. $J$ Ethnopharmacol 41: 71-76.

Mukherjee PK, Saha K, Murugesan T, Mandal SC, Pal M, Saha BP 1998. Screening of anti diarrhoeal profile of some plant extracts of a specific region of West Bengal, India. J Ethnopharmacol 60: 85-89.

Okhawa H, Qohishi N, Yagi K 1979. Assay of lipid peroxides in animal tissues by thiobarbituric acid reaction. Anal Biochem 95: 351-358.

Parameswari SA, Chetty CM, Chandra Sekar KB 2011. Phytochemical studies and anti-bacterial activity of Ficus benghalensis. Int J Phytochem Pharmacol 1: 83-87.

Peretti E, Karlaganis G, Lauterburg BH 1987. Acetylating of acetylhydrazine, the toxic metabolite of Isoniazid, in humans: inhibition by concomitant administration of Isoniazid. J Pharmacol Exp Ther 243: 686-689.

Rajesh KG, Achyut NK, Geeta W, Murthy PS, Ramesh C, Vibha T 2005. Nutritional and hypoglycemic effect of fruit pulp of Annona squamosa in normal healthy and alloxan-induced diabetic rabbits. Ann Nutr Metab 49: 407-413.

Ramaiah SK, Apte U, Mehendale HIM 2001. Cytochrome P4502E1 induction increases thioacetamide liver injury in diet-restricted rats. Drug Metab Dispos 29: 10881095.

Saleem TSM, Christina AJM, Chidambaranathan N, Ravi V, Gauthaman K 2008. Hepatoprotective activity of Annona squamosa Linn. on experimental animal model. Int $J$ Appl Res Nat Prod 1: 1-7.

Sarich TC, Youssefi M, Zhou T, Adams SP, Wall RA, Wright JM 1996. The role of hydrazine in the mechanism of isoniazid hepatotoxicity in rabbits. Arch Toxicol 70: $835-840$

Sharma SK 2004. Antituberculosis drugs and hepatotoxicity. Infect Genet Evol 4: 167-170.

Shukla R, Gupta S, Gambhir JK, Prabhu KM, Murthy PS 2004. Antioxidant effect of methanol extract of the bark of Ficus benghalensis in hypercholesterolaemic rabbits. $J$ Ethnopharmacol 92: 47-51.

Singh RK, Watal G 2010. Antimicrobial potential of Ficus 
benghalensis aerial roots. Int J Pharma Bio Sci 1: 1-3.

Singh RP, Murthy KNC, Jayaprakasha GK 2002. Studies on the antioxidant activity of Pomegranate (Punica granatum) peel and seed extracts using in vitro models. J Agr Food Chem 50: 81-86.

Skakun NP, Shmanko VV 1985. Synergistic effect of Rifampicin on hepatotoxicity of isoniazid. Antibiot Med Biotek 30: 185-189.

Steele MA, Burk RF, Des Prez RM 1991. Toxic hepatitis with Isoniazid and rifampicin: a meta-analysis. Chest 99: 465471.

Subramanian PM, Misra GS 1978. Chemical constituents of Ficus benghalensis. Pol J Pharmacol Pharm 30: 559562.

Tasduq SA, Peerzada K, Koul S, Bhat R, Johri RK 2005. Biochemical manifestation of anti-tuberculosis drugs induced hepatotoxicity and the effect of Silymarin. Hepatol Res 31: 132-135.

Taur DJ, Nirmal SA, Patil RY, Kharya MD 2007. Antistress and antiallergic effects of Ficus benghalensis bark in asthma. Nat Prod Res 21: 1266-1270.

Thakare VN, Suralkar AA, Deshpande AD, Naik SR 2010. Stem bark extraction of Ficus benghalensis Linn for antiinflammatory and analgesic activity in animal models. Ind J Exp Biol 48: 39-45.

The Wealth of India 1999. In: A Dictionary of Indian Raw
Materials and industrial products. Vol. 4. New Delhi: Council of Scientific and Industrial Research; p. 24-6.

Trease GE, Evans MC 1989. Text book of Pharmacognosy. London: Bailiere Tindall; p. 200-201, 340-348, 419-423, 626-630, 765-775.

$\mathrm{Wu}$ J, Leev S, Yeh P 1990. Isoniazid-Rifampicin induced hepatitis in hepatitis B carriers. GSGPTroentrology 98: 502-504.

Yadav S, Mayank K, Mradul G, Chandana VR, Veena S 2011. Elucidation of Analgesic and Antipyretic activities of Ficus benghalensis Linn. Leaves in rats. J Pharm Sci 1: 38-41.

Yasuda K, Sato A, Chida K 1990. Pulmonary tuberculosis with chemotherapy related liver dysfunction. Kekkadu 65: 407-413.

Yue J, Peng RX, Yang J, Kong R, Liu J 2004. CYP2E1 mediated isoniazid-induced hepatotoxicity in rats. Acta Pharmacol Sin 25: 699-704.

\section{*Correspondence}

\section{S. Angalaparameswari}

Department of Pharmaceutical Analysis, Annamacharya College of Pharmacy

Rajampet-516126, India

eswarisundar@rediffmail.com 